\title{
HUBUNGAN KEPATUHAN HEMODIALISIS DAN DUKUNGAN SOSIAL TERHADAP KEJADIAN RAWAT INAP ULANG PASIEN HEMODIALISIS
}

\author{
Sinta Wijayanti \\ Akademi Keperawatan Panca Bhakti Bandar Lampung \\ *E-mail: sinta.wija.wijayanti@gmail
}

\begin{abstract}
Abstrak
Rawat inap ulang pasien HD mememiliki dampak negatif terhadap pasien dan keluarga yaitu dapat meningkatkan beban emosional pasien dan keluarga sehingga menyebabkan turunnya kualitas hidup pasien. Tujuan penelitian ini adalah untuk mengetahui hubungan kepatuhan hemodialisis dan dukungan sosial terhadap kejadian rawat inap ulang pasien hemodialisis. Desain penelitian menggunakan pendekatan cross sectional dengan total sampel 111 pasien hemodialisis dengan teknik consecutive sampling. Instrumen yang digunakan dalam penelitian ini adalah intrumen kepatuhan HD dengan menggunakan 1 item pertanyaan mengenai hemodialisis dan ENRICHD Social Support Instrument (ESSI). Data diolah dengan menggunakan program software komputer dan dilakukan analisis bivariat menggunakan Mann Whitney. Hasil analisis menunjukkan bahwa terdapat hubungan yang signifikan antara kepatuhan hemodialisis $(\mathrm{p}-\mathrm{value}=0,032)$ dan dukungan sosial ( $\mathrm{p}$-value $=0,0,34$ ). Rekomendasi penelitian ini diharapkan perawat meningkatkan pemberian edukasi terhadap pasien dan keluarga tentang kepatuhan kehadiran hemodialisis.
\end{abstract}

Kata Kunci : Kepatuhan Hemodialisis, Dukungan Sosial, Rawat Inap Ulang

\begin{abstract}
Rehospitalization of HD patients has a negative effect on the patient and family which can improve the patient's emotional and family improve the quality of life of the patient. The purpose of this study was to study the relationship between hemodialysis consent and social support for the incidence of rehospitalization for hemodialysis patients. The study design used a cross sectional design with 111 samples of hemodialysis patients with consecutive sampling technique. The instrument used is the HD compliance instrument with using 1 item question regarding hemodialysis and ENRICHD Social Support Instrument (ESSI). Data were processed using computer software programs and performed bivariate analysis using Mann Whitney. The analysis showed a significant relationship between hemodialysis consent $(p$-value $=0.032)$ and social support $(p$-value $=0.0 .34)$. The recommendations of this study are expected nurses to increase educational assistance to patients and families regarding consent to attend hemodialysis.
\end{abstract}

Keywords: Hemodialysis Compliance, Social Support, Hospitalization

Dikirim: 20 Agustus 2019

Diterima: 19 September 2019

Terbit: 20 Oktober 2019 


\section{PENDAHULUAN}

Rawat inap ulang merupakan kembalinya pasien untuk diberikan perawatan secara terencana ataupun tidak dalam 30 sampai 90 hari setelah perawatan sebelumnya (Mathew et al, 2015; Sawhney et al, 2017). Rawat inap ulang terjadi pada pasien dengan berbagai karakteristik penyakit. Karakteristik penyakit tersebut yaitu CHF, COPD, kanker, stroke, demensia, dan gagal ginjal terminal (Greysen et al., 2017). Keenam karakteristik penyakit tersebut diketahui bahwa gagal ginjal terminal dengan hemodialisis merupakan jenis penyakit kedua setelah kanker yang memiliki resiko tinggi pasien di rawat inap ulang. (Greysen et al., 2017). Prevalensi terjadinya rawat inap ulang pasien hemodialisis yaitu sebanyak 30\% dengan rata-rata rawat ulang sebanyak 1 kali dalam setahun (UM-KECC, 2014; USRDS, 016).

Rawat inap ulang pasien HD memiliki dampak negatif pada pasien dan keluarga dengan meningkatkan beban emosional. Hal ini menyebabkan turunnya kualitas hidup pasien. Selain berdampak terhadap individu dan keluarga, rawat inap ulang pasien hemodialisis juga berdampak pada sistem kesehatan negara. Sistem kesehatan negara akan mengeluarkan biaya besar untuk mengobati dan merawat inap ulang pasien (Mathew et al, 2015; Flythe et al., 2016).

Laporan anggaran Medicare yang terpakai untuk rawat inap ulang pasien tahun 2012 mencapai 17 miliar dolar per tahun dan mempengaruhi $15-30 \%$ anggaran tersebut dan meningkat pada tahun 2014 mencapai 40\% dari total pengeluaran Medicare (UM-KECC, 2014; Mathew et al, 2015; Flythe et al., 2016). Di Indonesia, pembiayaan BPJS Kesehatan untuk penyakit ginjal merupakan pembiayaan terbesar kedua setelah penyakit jantung. Pada tahun 2014 pembiayaan BPJS Kesehatan untuk penyakit ginjal sebesar 2,2 trilliun rupiah dan meningkat sebanyak 2,7 trilliun rupiah pada tahun 2015 (Infodatin, 2017).

Rawat inap ulang pasien HD tersebut dapat terjadi karena berbagai alasan. Menurut Djukanovic, 2015; Mathew et al., 2015; Jasinski, 2017) bahwa kepatuhan HD dapat menyebabkan pasien dirawat inap ulang karena dapat meningkatkan resiko komplikasi dari HD. Lebih lanjut, terdapat penelitian yang menyatakan bahwa kepatuhan HD tidak berpengaruh terhadap penurunan angkat rawat inap ulang pasien HD (Jensen et al., 2015).

Selain kepatuhan HD, rawat inap ulang pasien juga dapat terjadi karena dukungan sosial. Menurut Kara, Caglar, \& Kilic, (2007) bahwa dukungan sosial pada pasien HD secara signifikan akan mempengaruhi penerimaan informasi kesehatan oleh pasien dan dapat menurunkan kejadian rawat inap ulang pasien gagal ginjal terminal dengan hemodialisis (Greysen, 2015). Lebih lanjut, terdapat penelitian yang menyatakan bahwa kepatuhan 
HD tidak berpengaruh terhadap kejadian rawat inap ulang (Jasinski, 2017).

Melihat hasil beberapa penelitian di atas diketahui bahwa masih terdapat beberapa perbedaan pendapat mengenai kepatuhan HD dan dukungan sosial sebagai faktor resiko terjadinya rawat inap ulang pasien HD. Berdasarkan uraian tersebut penulis tertarik melakukan penelitian mengenai hubungan kepatuhan HD dan dukungan sosial terhadap kejadian rawat inap ulang pasien HD di RS Dr. H. Abdoel Moeloek Provinsi Lampung.

\section{METODOLOGI}

Penelitian ini menggunakan desain cross sectional. Total sampel pada penelitian ini adalah 111 orang. Kriteria inklusi sampel penelitian yaitu 1) Pasien yang telah menjalani hemodialisis rutin minimal selama 3 bulan, 2) Pasien yang pernah menjalani rawat inap ulang minimal $1 \mathrm{x}$ selama rentang waktu 12 bulan terakhir. Kriteria eksklusi sampel penelitian yaitu 1) Adanya riwayat rawat karena penyakit berat seperti: kanker, infeksi akses vaskular, dan penyakit infeksi lain (TB, hepatitis, dan HIV), 2) Adanya riwayat rawat karena ketidakstabilan gula darah, 3) Tidak hadir sebanyak 4x sesi hemodialisis berturut-turut,

Instrumen yang digunakan yaitu intrumen kepatuhan HD yaitu dengan menggunakan 1 item pertanyaan mengenai hemodialisis.
Lebih lanjut peneliti juga menggunakan instrumen dukungan sosial yaitu dengan menggunakan ENRICHD Social Support Instrument (ESSI) yang berisi 7 item pertanyaan. Data diolah pada program computer dan dianalisis secara univariat dan bivariat menggunakan uji Mann Whitney untuk mengetahui hubungan antara dua variabel. Pengambilan data penelitian dilakukan sesuai dengan etika penelitian dengan menerapkan prinsip penelitian meliputi beneficence and non maleficence, respect for human dignity, dan justice (Polit \& Back, 2012).

\section{HASIL}

\section{Analisis Univariat}

Tabel 1. Distribusi Frekuensi Kepatuhan HD

\begin{tabular}{lcc}
\hline \multicolumn{1}{c}{ Kepatuhan HD } & Frekuensi & Persentase (\%) \\
\hline Tidak Patuh & 38 & 34,2 \\
\hline Patuh & 73 & 65,8 \\
\hline
\end{tabular}

diketahui proporsi pasien yang patuh terhadap kepatuhan HD lebih banyak $(65,8 \%)$ dibanding dengan yang tidak patuh terhadap kepatuhan HD sebesar $(34,2 \%)$.

Tabel 2. Distribusi Dukungan Sosial

\begin{tabular}{lcc}
\hline \multicolumn{1}{c}{ Kepatuhan HD } & Frekuensi & Persentase (\%) \\
\hline Rendah & 65 & 58,6 \\
\hline Tinggi & 46 & 41,4 \\
\hline
\end{tabular}

diketahui proporsi pasien dengan dukungan sosial rendah lebih besar ( 58,6\%) dibanding dengan dukungan sosial tinggi $(41,4 \%)$. 
Tabel 3. Distribusi Kejadian Rawat Inap Ulang

\begin{tabular}{ccc}
\hline Variabel & Median & Min-Maks \\
\hline Kejadia Rawat Inap Ulang & 2 & $2-8$ \\
\hline
\end{tabular}

Berdasarkan tabel diketahui bahwa nilai tengah (median) kejadian rawat inap ulang responden adalah 2 dengan nilai kejadian rawat inap ulang paling sedikit terjadi 2 kali dan terbanyak terjadi 8 kali.

Tabel 4. Analisis Hubungan Kepatuhan Hemodialisis dan Dukungan Sosial dengan Rawat Inap Ulang

\begin{tabular}{ll}
\hline \multicolumn{1}{c}{ Variabel } & p-value \\
\hline Kepatuhan HD & 0,032 \\
\hline Dukungan Sosial & 0,034 \\
\hline
\end{tabular}

Berdasarkan analisis bivariat diketahui terdapat hubungan yang signifikan antara kepatuhan HD $(\mathrm{p}$-value $=0,032)$ dan dukungan sosial $(\mathrm{p}$-value $=$ $0,034)$ terhadap kejadian rawat inap ulang pasien.

\section{PEMBAHASAN}

Berdasarkan hasil penelitian didapatkan rentang rawat inap responden dalam penelitian ini adalah 2 sampai 8 kali rawat inap. Rentang rawat inap responden dalam penelitian ini berbeda dengan penelitian yang dilakukan oleh Hakim \& Collins, (2014) yaitu 1,2 sampai 3,3 kali rawat inap dalam 30 hari.

Rata-rata kejadian rawat inap ulang pasien gagal ginjal terminal dengan hemodialisis pada penelitian ini adalah 2,72 kali. Rata-rata kejadian rawat inap ulang dalam penelitian ini lebih tinggi dibandingkan data rata-rata kejadian rawat ulang yang dimiliki oleh (Hickson et al., 2018) dan US Renal Data
System (2016). Pada penelitian Hickson et al., (2018) diketahui bahwa rata-rata kejadian rawat inap ulang yaitu 2,20 kali. Lebih lanjut menurut US Renal Data System (2016) diketahui bahwa rata-rata kejadian rawat inap ulang yaitu 1 kali rawat ulang atau 2 kali rawat inap dalam setahun.

Hasil penelitian menunjukkan proporsi responden berdasarkan tingkat kepatuhan HD dimana pasien yang patuh terhadap kepatuhan HD lebih besar yaitu 64,9\% (72 orang) dibandingkan responden yang tidak patuh yaitu 35,1\% (39 orang). Berdasarkan hasil penelitian tersebut diketahui bahwa sebagian besar responden patuh terhadap kepatuhan HD. Hal ini sesuai dengan hasil penelitian yang dilakukan oleh Jensen et al., (2015); Young, Hertzog, \& Barnason, (2016) dimana dinyatakan bahwa kepatuhan tidak berpengaruh terhadap penurunan kejadian rawat inap ulang.

Hasil uji Man Whitney ada hubungan yang signifikan antara kepatuhan HD dengan kejadian rawat inap ulang ( $\mathrm{p}$-Value $=0,032$ ). Berdasarkan hasil analisis tersebut didapatkan bahwa rata-rata ketidakpatuhan HD dapat meningkatkan kejadian rawat inap ulang sebesar 17,51 kali, yaitu dari 49,85 kali menjadi berubah naik 67,36 kali. Hasil penelitian ini sesuai dengan penelitian yang dilakukan oleh Djukanovic, (2015); Chan, Zalilah, Hii, (2012); Mathew et al, (2015); Jasinski, (2017); Napitupulu, (2015) dimana dinyatakan bahwa ketidakpatuhan HD dapat 
mempengaruhi rawat inap ulang pasien hemodialisis. Ketidakpatuhan terhadap kepatuhan HD akan menyebabkan kegagalan regimen hemodialisis dan merugikan pasien hemodialisis dengan meningkatkan peningkatan resiko komplikasi medis (Chan, Zalilah, Hii, 2012). Pasien GGT dengan HD harus mampu menjalankan kepatuhan HD agar menjaga fungsi organ, menghindari kelebihan cairan, mengeluarkan sampahsampah dan racun dalam darah sehingga dapat mencegah terjadinya rawat inap ulang pasien GGT dengan HD (Djukanovic, 2015; Chan, Zalilah, Hii, 2012; Napitupulu, 2015).

Hasil uji Man Whitney ada hubungan yang signifikan antara dukungan sosial dengan kejadian rawat inap ulang ( $\mathrm{p}$-Value $=0,034)$. Rata-rata dukungan sosial rendah dapat meningkatkan kejadian rawat inap ulang yaitu dari 49,35 kali menjadi berubah naik 60,71 kali. Hal tersebut sesuai dengan penelitian yang dilakukan oleh Flythe, Hilbert, Kshirsagar. \& Gilet, (2017) yang menyatakan bahwa ada hubungan yang signifikan antara dukungan sosial terhadap kejadian rawat inap ulang dengan $\mathrm{p}$ value $=0,04$.

Pasien Hemodialisis (HD) mengalami beban psikososial yang luar biasa yang disebabkan karena keterbatasan penyakit kronis dan keterpaksaan akibat perubahan gaya hidup. Dukungan sosial secara efektif akan mempengaruhi stress, depresi, penerimaan penyakit, dan beban penyakit yang dirasakan akibat penyakit kronis seperti gagal ginjal terminal (Theodoritsi et al., 2016). Lebih lanjut penelitian yang dilakukan oleh Kara, Caglar, \& Kilic, (2007) menunjukkan bahwa dukungan sosial pada pasien HD secara signifikan akan mempengaruhi penerimaan informasi kesehatan oleh pasien, mengikuti terapi yang disarankan oleh petugas kesehatan, menjalankan kepatuhan diet, dan penerimaan ketergantungan hidup dengan mesin hemodialisis.

\section{KESIMPULAN}

Berdasarkan hasil penelitian dapat disimpulkan bahwa terdapat hubungan antara kepatuhan hemodialisis $(0,032)$ dan dukungan sosial $(\mathrm{p}$-value $=0,034)$ terhadap kejadian rawat inap ulang pasien hemodialisis. Lebih lanjut diharapkan untuk meningkatkan pemberian edukasi terhadap pasien dan keluarga tentang kepatuhan kehadiran hemodialisis. Edukasi diberikan dengan harapan dapat meningkatkan kepatuhan dan menurunkan rawat inap ulang pasien hemodialisis.

\section{KEPUSTAKAAN}

Chan, Y. M., Zalilah, M. S., \& Hii, S. Z. (2012). Determinants of compliance behaviours among patients undergoing hemodialysis in malaysia. PLOS ONE,

Djukanovic (2015). Compliance with guidelines and predictors of mortality in hemodialysis. Learning from Serbia patients. Nefrologia. 2015;35(3):28795. doi: 10.1016/j.nefro.2015.02.003.

Flythe, J. E., Hilbert, J., Kshirsagar, A. V., \& Gilet, C. A. (2017). Psychosocial factors and 30-day hospital readmission among individuals receiving 
maintenance dialysis: a prospective study. American Journal of Nephrology, 45(5), 400-408.

Flythe, J. E., Katsanos, S. L., Hu, Y., Kshirsagar, A. V., Falk, R. J., \& Moore, C. R. (2016). Predictors of 30-day hospital readmission among maintenance hemodialysis patients: A hospital's perspective. Clinical Journal of the American Society of Nephrology, 11(6), 1005-1014.

Greysen, S. R., Harrison, J. D., Kripalani, S., Vasilevskis, E., Robinson, E., Metlay, J., Auerbach, A. D. (2017). Understanding patient-centred readmission factors: A multi-site, mixed-methods study. BMJ Quality and Safety, 26(1), 33-41. https://doi.org/10.1136/bmjqs-2015004570

Gresen, S. R., Harrison, J. D., Kripalani, S., Vasilevskis, E., Robinson, E., Metlay, J., Auerbach, A. D. (2017). Understanding patient-centred readmission factors: A multi-site, mixed-methods study. BMJ Quality and Safety, 26(1), 33-41.

Jasinski, M. J. (2017). Family consultation to reduce early hospital readmissions among patients with end-stage renal disease : a randomized clinical trial by Submitted to the graduate school of wayne state university, Detroit, Michigan in partial fulfillment of the requiremen.

Jensen et al. (2015). Shortage of peritoneal dialysis solution and the food and drug administration's response. Clinical Journal of the American Society of Nephrology 10 (8), 1484-1486, 2015

Hakim, R. M., \& Collins, A. J. (2014). Reducing avoidable rehospitalization in esrd: a shared accountability. Journal of the American Society of Nephrology, 25(9), 1891-1893.

Hickson, L. J., Thorsteinsdottir, B., Ramar, P., Reinalda, M. S., Crowson, C. S., Williams, A. W., Shah, N. D. (2018). Hospital readmission among new dialysis patients associated with young age and poor functional status. Nephron, 139(1),
Infodatin. (2017). Situasi penyakit ginjal kronis. Jakarta. Pusat Data dan Informasi

Kara, B., Caglar, K., \& Kilic, S. (2007). Nonadherence with diet and fluid restrictions and perceived social support in patients receiving hemodialysis. Journal of Nursing Scholarship, 39(3), 243-248.

Mathew, A. T., Strippoli, G. F. M., Ruospo, M., \& Fishbane, S. (2015). Reducing hospital readmissions in patients with end-stage kidney disease. Kidney International, 88(6), 1250-1260. 7

Napitupulu. (2015). Hubungan kepatuhan menjalankan terapi (diet, hemodialisia, cairan) dengan kejadian rawat inap ulang pada pasien gagal ginjal kronis di RS Awal Bros Tangerang 2015. Tesis : Universitas Esa Unggul.

Polit \& Beck. (2012). Nursing research: generating and assessing evidence for nursing practice. China: Lippincons Williams \& Wilkins

Sawhney, S., Marks, A., Fluck, N., McLernon, D. J., Prescott, G. J., \& Black, C. (2017). Acute kidney injury as an independent risk factor for unplanned 90-day hospital readmissions. BMC Nephrology, 18(1), $1-14$.

Theodoritsi, A., Aravantinou, M.-E., Gravani, V., Bourtsi, E., Vasilopoulou, C., Theofilou, P., \& Polikandrioti, M. (2016). Factors associated with the social support of hemodialysis patients. Iranian Journal of Public Health, 1261-1269.

UM-KECC. (2014). Report for the standardized readmission ratio, 1-39.

USRDS. (2016). 2016 USRDS annual data report :, 2. Disease, K., Volume, U. S., \& States, U

Young, L., Hertzog, M., \& Barnason, S. (2016). Effects of a home-based activation intervention on selfmanagement adherence and readmission in rural heart failure patients: The PATCH randomized controlled trial. BMC Cardiovascular Disorders, 16(1), 1-11. https://doi.org/10.1186/s12872016-0339-7 